\title{
Facebook como Herramienta Didáctica Mediadora para Favorecer el Desarrollo de las Habilidades Básicas del Idioma Inglés
}

\author{
Luis Enrique Saavedra Torres ${ }^{1}$ \\ Franklin Jesús Solís Zúniga ${ }^{2}$
}

\section{RESUMEN}

La red social Facebook presenta herramientas idóneas para ser utilizadas por docentes y estudiantes en procesos educativos, se requiere de una planeación didáctica adecuada para su aprovechamiento. En estas épocas las y los estudiantes hablan de Facebook y algunas otras Tecnologías de la Información y la Comunicación; herramientas que son utilizadas para el ocio, diversión y en algunos pocos casos para la educación y formación personal. La experiencia de investigación que aquí se presenta está orientada en demostrar de qué manera el uso de la red social Facebook como herramienta didáctica mediadora favorece el desarrollo de las habilidades básicas del idioma Inglés. El estudio se llevó a cabo en la Facultad Regional Multidisciplinaria FAREMEstelí, con estudiantes de la carrera Licenciatura en Inglés durante el periodo 2015. Se realizó a partir del diseño de investigación mixto con predominio del enfoque cualitativo, descriptivo y de corte transversal. Las técnicas aplicadas para la recolección de la información fueron: encuesta, observación, entrevista y análisis documental. Los resultados reflejan que la gran mayoría de docentes y estudiantes tienen perfil en la red social Facebook, los docentes no hacen uso de Facebook como herramienta didáctica desaprovechando las bondades que posee, y los estudiantes demandan actividades educativas en otros tipos de ambientes. Se encontró debilidad en el uso de TIC por los docentes, herramientas necesarias para favorecer el desarrollo de las habilidades básicas del idioma Inglés.

Palabras clave: Red social Facebook, Herramienta Didáctica Mediadora, Habilidades Básicas del Idioma Inglés, Estrategias Didácticas, Plan de capacitación.

Recibido: 23 de febrero de 2016

Aceptado: 13 de junio de 2016

1 Egresado de la Maestría: Pedagogía con Mención en Docencia Universitaria. Docente. Universidad Nacional Autónoma de Nicaragua, Managua. Facultad Regional Multidisciplinaria, Estelí. Correo electrónico: lest2109@gmail.com 2 Psicólogo-Docente. Universidad Nacional Autónoma de Nicaragua. Facultad Regional Multidisciplinaria de Estelí. Master en Psicología, Atención Personalizada y Desarrollo Comunitario. UAB. España. Doctorando en Ciencias en Salud Pública. Universidad de Guadalajara. México. Correo electrónico: franksolis23@yahoo.com 


\title{
Facebook as a didactic tool in the development of English language skills
}

\begin{abstract}
The social network Facebook offers suitable tools to be implemented by teachers and students in educative processes. An appropriate didactic planning is required for its use. In modern times, students talk about Facebook and some other Information and Communication Technologies (ICT), tools that are used for entertainment purposes and in a few cases for educational purposes. This study is oriented to show the way in which the use of Facebook as a didactic tool can contribute to the development of English language skills. The study was carried out at Facultad Regional Multidisciplinaria FAREM-Estelí, with students of the English teaching program, during the academic year 2015. The study was carried out using a mix methods design, with predominance of the qualitative approach. The data collection techniques implemented were survey, observation, interview and document analysis. The main research results reveal that the majority of teachers and students have a Facebook profile; however, they do not use it as a didactic tool. Moreover, weaknesses regarding the use of ICT tools were found among teachers, tools that are necessary in the development of English language skills.
\end{abstract}

Keywords: Social Network Facebook, Didactic Tool, English Language Skills, Training Program. 


\section{INTRODUCCIÓN}

En la Facultad Regional Multidisciplinaria, es común identificar que el interés principal que muestra el estudiante sobre el idioma Inglés es hablarlo fluidamente, comunicarse de manera rápida, sin errores y pronunciarlo correctamente. Estos son los objetivos primordiales del estudiante, lamentablemente, los temores existentes en ellos así como las limitaciones en cuanto a la metodología utilizada para la enseñanza de este idioma, impiden en muchos casos el alcance de estos objetivos.

Se ha identificado que los problemas más relevantes al momento de aprender Inglés se involucran en el desarrollo de las habilidades básicas. Por ello, esta investigación se enfoca a resolver la problemática formulada a continuación:

¿De qué manera el uso de la red social Facebook como herramienta didáctica mediadora favorece el desarrollo de las habilidades básicas del idioma Inglés en estudiantes de la carrera Licenciatura en Inglés de la FAREM Estelí, en el periodo 2015?

Como antecedente de este estudio se destaca el "Uso Educativo de Facebook por el Docente Universitario" presentado por los autores López \& Espinoza (2013). El trabajo se realizó en el Centro Universitario del Sur, de la Universidad de Guadalajara. Algunos de los resultados obtenidos, reflejan que sí hay un uso educativo dirigido de Facebook, y que ésta plataforma puede ser un importante apoyo en los procesos de enseñanza y aprendizaje siempre y cuando se cuente con un diseño adecuado y acorde a los contenidos educativos trabajados.

Por su parte Rojas Bonilla (2013), llevó a cabo un estudio titulado "Reforzando el aprendizaje del idioma Inglés en el aula con el apoyo y uso de las TIC" presentado en la Universidad Autónoma del Estado de Hidalgo - México. Este estudio se enfocó en mostrar cómo es que los recursos web 2.0 (videos, audios y blog) son de gran utilidad para mejorar la habilidad oral en Inglés de los alumnos. La metodología se basa en la implementación de recursos web 2.0 en el aula mediante el uso de diferentes actividades educativas con estrategias diseñadas por la docente para aumentar la práctica oral en Inglés de las y los estudiantes. Al final del curso, aparte de las evaluaciones de las cuatro habilidades del idioma Inglés, se les aplicó a las y los estudiantes otro examen de diagnóstico para conocer si durante el curso adquirieron otras o reforzaron las habilidades orales que ya tenían sobre el idioma. El resultado fue satisfactorio, ya que los estudiantes obtuvieron un resultado mayor al del examen de diagnóstico inicial.

En este estudio cuyo objetivo es: Demostrar de qué manera el uso de la red social Facebook como herramienta didáctica mediadora favorece el desarrollo de las habilidades básicas del idioma Inglés, en estudiantes de la carrera Licenciatura en Inglés de FAREM Estelí, se diseñó un plan de capacitación dirigido a los docentes donde se incorporan actividades con los recursos que Facebook tiene y que pueden ser aprovechados en procesos educativos. Además, se pretende ofrecer una pequeña aportación a la línea de investigación Tecnologías de la Información y Comunicación con el tema redes sociales y su impacto en la sociedad, así como la línea de investigación calidad educativa con el tema Tecnología Educativa, particularmente: las TIC en los procesos de aprendizaje.

La hipótesis fue que si las y los docentes utilizan la red social Facebook como herramienta didáctica mediadora entonces se logrará el desarrollo de las habilidades básicas del idioma Inglés (listening, speaking, reading y writing) así como las competencias (comprensión auditiva, pronunciación, gramática y vocabulario) en las y los estudiantes. Dicha hipótesis será comprobada una vez que se ponga en marcha el plan de capacitación para docentes propuesto en este estudio. 
El estudio se realizó bajo el enfoque mixto debido a que se recolectaron, analizaron y vincularon datos cuantitativos y cualitativos, predominando el enfoque cualitativo porque se aplicaron técnicas como: entrevista, observación y análisis documental.

El pensar en cómo se puede utilizar el Facebook desde una perspectiva educativa hace necesario analizar cómo éste favorece el desarrollo de habilidades básicas del idioma Inglés que pueden mejorar a partir de la práctica de la escucha, habla, lectura y la escritura, partiendo de la motivación que puede sentir el estudiante al usar el Facebook como tarea colaborativa al intercambiar experiencias con sus compañeros. (Tobón, 2006, pág. 222).

Se espera que los hallazgos de esta investigación sean de gran importancia para las y los estudiantes porque los beneficiaría en su aprendizaje, ya que, realizarían actividades colaborativas que rompen con los esquemas de métodos tradicionales que, en ocasiones, son aburridos para ellos, especialmente, para los aficionados a las TIC.

De hecho, el impacto que se cree que genera el uso del Facebook en el aula es positivo puesto que, al observar la espontaneidad, la motivación, la agilidad y la participación con la que escriben en Facebook, ya sea desde una computadora o de sus dispositivos móviles, se hace necesario plantear actividades que lo incluyan para obtener los mismos beneficios actitudinales que manifiestan las y los estudiantes cuando están conectados.

Se pretende que con el análisis de los resultados se facilite información y avances para mejorar la práctica pedagógica educativa de las y los docentes, ya que el descubrir cómo Facebook puede convertirse en una herramienta de apoyo a los aprendizajes de las y los estudiantes, no sólo de la carrera de Inglés sino de otras carreras, será de gran relevancia puesto que, podrán incorporar a sus clases actividades más motivadoras y atractivas para las y los estudiantes.
"El descubrir una posibilidad pedagógica en el uso del Facebook, anima a las y los docentes a permitirlo en el aula, dado que, la utilización de la tecnología en las clases debe ser como medio y recurso didáctico, puesto que, por sí sola no resolverá las problemáticas dentro del ámbito educativo" (Cabero \& Gisbert, 2005, pág. 48).

En suma, la comunidad educativa en general se verá beneficiada con la inclusión del Facebook al aula de clase porque dejarán a un lado el tabú que existe sobre dicha red social, como una pérdida de tiempo. Asimismo, es una oportunidad de enseñar a las y los estudiantes de la manera que ellos quieren aprender, en un contexto de comunicación real, con comentarios y saludos propios de quienes consideran sus amigos. "Lo que implica, partir de los gustos y de los intereses de las y los estudiantes, dado que, el uso de las TIC, genera impacto y atracción en los procesos educativos si se utilizan apropiadamente". (Marqués, 2012)

Los resultados más relevantes revelan que Facebook es la red social más utilizada por docentes y estudiantes de la carrera de Inglés razón por la cual es necesaria su valoración para ser utilizada como herramienta didáctica. Estudiantes y docentes consideran que al utilizar Facebook como herramienta didáctica y de aprendizaje se lograría desarrollar las habilidades básicas del idioma Inglés.

Las actividades que se pueden realizar en Facebook con el fin de favorecer el desarrollo de las habilidades básicas son: Grabar voz en Inglés, grabar vídeos de conversaciones en Inglés, leer contenido educativo en Inglés, reflexionar sobre imágenes con mensajes en Inglés, ver películas educativas en Inglés, conversaciones grupales sobre un contenido en Inglés y realizar actividades interactivas en Inglés (crucigramas, rellenar huecos, test, emparejamiento, verdadero y falso). 


\section{MATERIALES Y MÉTODOS}

Para esta investigación educativa, cuyo problema es, el desarrollo de las habilidades básicas del idioma Inglés, el estudio se realizó bajo el enfoque mixto el cual según Hernández, Fernández, \& Baptista (2006, pág. 755) es "un proceso que recolecta, analiza y vincula datos cuantitativos y cualitativos en un mismo estudio o una serie de investigaciones para responder a un planteamiento del problema".

Se determinó que es un estudio con enfoque mixto desde el planteamiento del tema, objetivos y además, porque se recolectaron datos cuantitativos a través de la aplicación de una encuesta, sin embargo, existe predominio del enfoque cualitativo porque se aplicaron más técnicas de recolección de datos cualitativos como la entrevista, observación y análisis documental.

Según su aplicabilidad es una investigación aplicada ya que se hace una propuesta de plan de capacitación para docentes que incorpora la red social Facebook como herramienta didáctica con el objetivo de favorecer el desarrollo de las habilidades básicas del idioma Inglés en las y los estudiantes de dicha carrera, además, esta investigación tiene un alcance descriptivo ya que, como señalan Hernández, Fernández, \& Baptista (2006), busca especificar los cambios importantes contando y detallando lo que se observó.

Es de corte transversal puesto que se realizó en el período de Marzo a Diciembre del año 2015 en la Facultad Regional Multidisciplinaria Estelí (FAREMEstelí). Los participantes en este estudio fueron 138 estudiantes de la carrera Licenciatura en Inglés, así como 7 docentes que guiaron el aprendizaje de asignaturas relacionadas con el idioma Inglés. Se utilizó el muestreo no probabilístico por conveniencia para seleccionar a los participantes, esto por la facilidad de reclutamiento al momento de solicitar la información. Los métodos generales utilizados para el análisis e interpretación de datos fueron la inducción y deducción así como el análisis y la síntesis. Las técnicas aplicadas para la recolección de datos fueron: la observación, la entrevista semiestructurada, análisis documental del modelo educativo y programas de asignaturas así como la encuesta. La observación se aplicó en los salones de clases, la entrevista fue realizada a docentes y la encuesta aplicada a estudiantes y docentes de la carrera Licenciatura en Inglés.

El Procesamiento y análisis de datos cualitativos se realizó de la siguiente manera:

1. Obtener la información: Esta se hizo a través del registro sistemático de notas de campo.

\section{Capturar, transcribir y ordenar la información:} la captura de la información se hizo a través de registro electrónico y registró en papel.

3. Codificar la información: Se agrupó la información obtenida en categorías que concentran las ideas, conceptos o temas similares descubiertos en el estudio.

4. Integrar la información: Aquí se relacionó las categorías obtenidas en el paso anterior, entre sí y con los fundamentos teóricos de la investigación.

En lo referente al análisis de los datos se utilizó la técnica análisis de contenido temático y la triangulación de datos. El procesamiento y análisis de los datos cuantitativos se hizo de acuerdo a los objetivos formulados en el estudio, utilizando la técnica de la encuesta para la recolección de datos. Para el procesamiento de la información se hizo necesaria la utilización de software estadísticos tales como: SPSS, Encuesta Fácil y Excel.

La principal limitante surgió al momento de solicitar información a las y los docentes de las asignaturas relacionadas con el idioma Inglés, solo tres docentes contestaron a la petición de apoyo por parte del investigador, por eso al final se decide trabajar solo con las y los docentes que estuvieron anuentes a brindar la información solicitada. 


\section{RESULTADOS Y DISCUSION}

\section{Concepciones que tienen docentes y estudiantes} de la carrera de Inglés sobre el uso de la red social Facebook como herramienta de aprendizaje.

El Gráfico 1, refleja que el uso de las redes sociales en pleno siglo XXI se ha convertido en una de las principales necesidades de la comunidad estudiantil.

En el contexto educativo, se han utilizado las redes sociales por la libertad que permiten para ser adaptadas a cualquier tipo de uso; uno de los usos educativos es que permite el intercambio de información mediante una plataforma institucional a través de internet; la cual ofrece el flujo de la información de interés para un grupo determinado; proporciona el consenso para la organización de actividades y promueven el aprendizaje colaborativo (Castells, 2011).

El $100 \%$ de los docentes informantes utilizan redes sociales dato muy importante sobre el uso de las TIC por parte de los docentes.

\section{¿Utilizas alguna red social?}

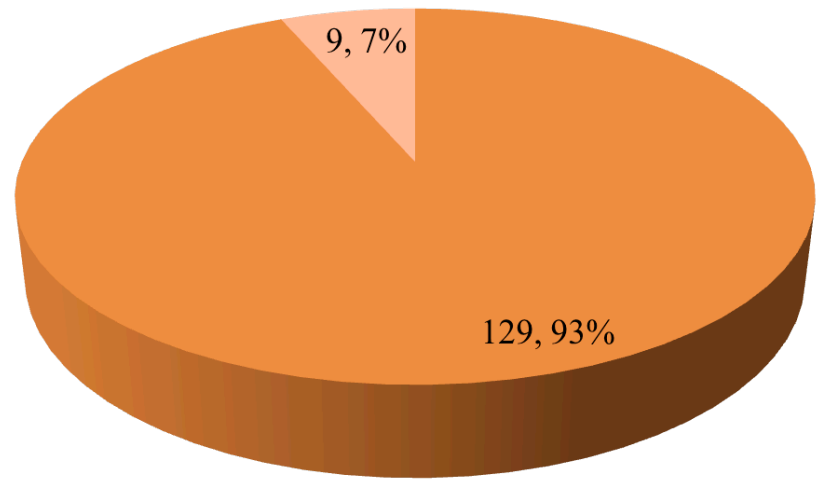

$\square \mathrm{Si}$ No

Gráfico 1, Uso de las redes sociales por estudiantes

\section{¿Cuál o cuáles de estas redes sociales utilizas?}

$\varpi$ Twitter $\square$ Linkedin $\square$ Facebook $\square$ Tuenti $\backsim$ Google Plus $\backsim$ Instagram

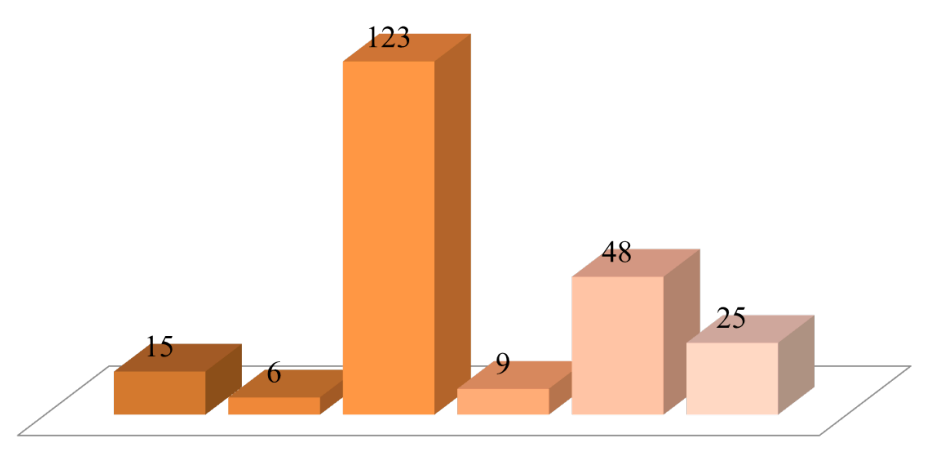

Gráfico 2, Redes sociales utilizadas por estudiantes

La red social Facebook es la más utilizada por las y los estudiantes de la carrera de Inglés, de esta manera Facebook se constituye como una herramienta de aprendizaje idónea para incorporar en la enseñanza del idioma Inglés sobre todo para el desarrollo de las habilidades básicas de dicho idioma.

Todos los docentes participantes en este estudio tienen un perfil en la red social Facebook convirtiéndose en la más utilizada, por ende la más indicada para usar como herramienta didáctica y así poder incorporar otros ambientes de aprendizaje donde los estudiantes se sienten motivados y dispuestos a participar.

El $88 \%$ de las y los estudiantes participantes en el estudio consideran que el uso de la red social Facebook favorece el desarrollo de las habilidades básicas del idioma Ingles, solo el 12\% no ve en Facebook una herramienta educativa.

¿Consideras que el uso de la red social Facebook favorece el desarrollo de las habilidades básicas del idioma Inglés?

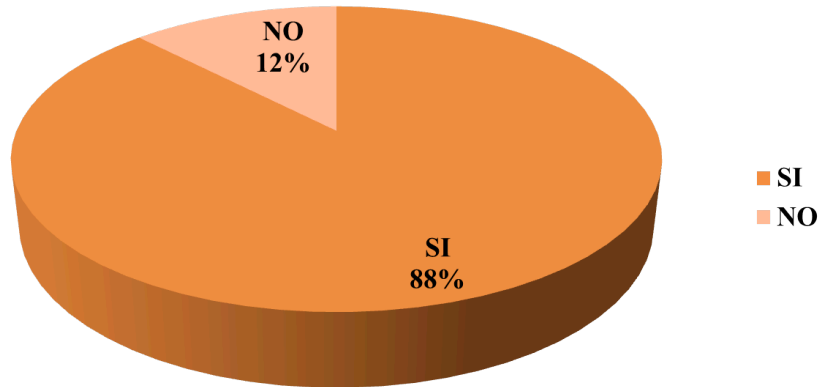

Gráfico 3, Facebook en el desarrollo de las habilidades básicas del idioma Inglés 
Pérez-Sabater (2012), menciona que el Marco de Referencia Europeo para la enseñanza y aprendizaje de idiomas recomienda la planificación de actividades en entornos tecnológicos, que permitan interacciones entre estudiante - estudiante y entre estudiante profesor, para activar la práctica de las habilidades orales de comprensión y producción. Y, de esa manera, se solucionen dos problemas que ocurren en el aula presencial, como son: (a) la falta de la interacción profesor - estudiante, y (b) la práctica oral continúa del estudiante.

Se puede afirmar que, las y los estudiantes en la actualidad, ya se conectan virtual y socialmente sin necesidad de la existencia de un currículum. Lo que hace falta desde las instituciones educativas es que las conexiones sociales y virtuales que se den en las redes sociales tengan una orientación pedagógica, para cumplir con la política educativa ya existente y normada en el marco curricular y alinearla al contexto de buen uso del Facebook a nivel mundial.

El Gráfico 4, expresa que las y los estudiantes consideran que al utilizar Facebook como herramienta de aprendizaje se podrían desarrollar las habilidades de escucha, habla, lectura y escritura del idioma Inglés. De esta manera, Facebook permite conversaciones multidimensionales tanto entre estudiante-estudiante y entre estudiante-profesor. Con estas características, Facebooktieneunimpactosignificativo en el aprendizaje de idiomas, porque proporciona oportunidades para entablar conversaciones informales y también permite el acceso a materiales auténticos como el intercambio de fotos, videos y música culturalmente relevantes. Es decir permite un aprendizaje de idiomas socialmente activo.

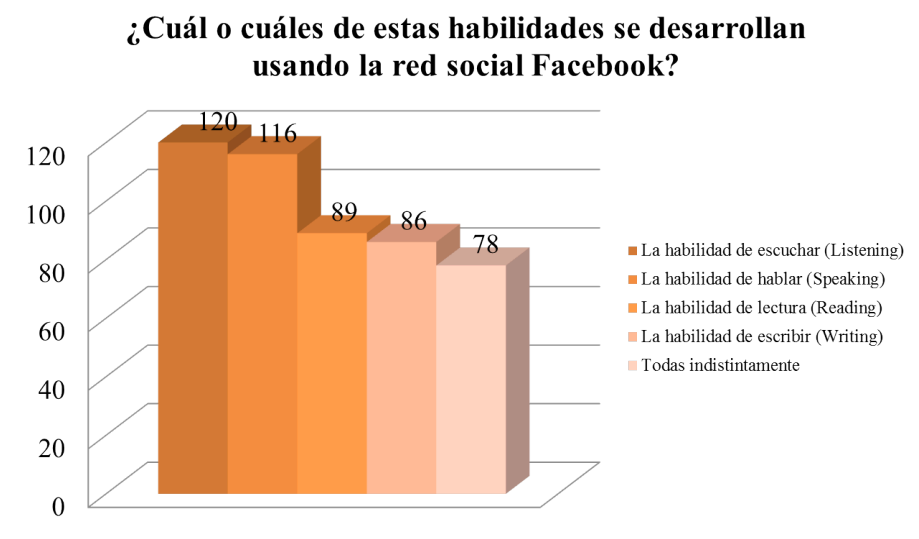

Gráfico 4, Habilidades básicas del idioma Inglés

Al consultar a los docentes sobre, ¿Cuál es su valoración sobre el uso que los estudiantes le dan a la red social Facebook? Los resultados fueron los siguientes:

- El docente 1 respondió “Las redes sociales son utilizada por los estudiantes solo para uso personal, mi percepción es que los estudiantes casi no utilizan Facebook para estudiar".

- El docente 2 respondió: "va en dependencia como lo utilizan si es para trabajos académicos creo que les es de mucho provecho"

- El docente 3 respondió: "En mi humilde opinión, el uso es meramente de comunicación y entretenimiento".

En síntesis, los docentes consideran que el uso que los estudiantes le dan al Facebook es de entretenimiento y comunicación, además aducen que si los estudiantes utilizaran el Facebook académicamente les seria de mucho provecho.

\section{Estrategias didácticas que están utilizando las y los docentes para favorecer el desarrollo de habilidades básicas del idioma Inglés en las y los estudiantes.}

De acuerdo con Tobón (2006), en el campo de la Pedagogía, las estrategias didácticas son la manera como el docente propone, de manera sistémica, que se desarrolle un aprendizaje, pueden ser exposiciones, diálogos, foros, debates, escuchar un programa radial o ver una película para discutirla en clase. 
No se observó el uso de las Tecnologías de la Información (TIC) como medio de enseñanza por parte de los docentes, contrario a lo que proponen los programas de estudio de las asignaturas Gramática I, Inglés integral I e Inglés integral II, mencionan que el uso de TIC es de suma importancia para la enseñanza de un idioma extranjero, ya que el estudiante necesita estar en constante práctica no solo dentro del aula sino fuera de ella, tal es el caso del uso de internet.

Los docentes utilizan diferentes estrategias para mejorar la gramática creando situaciones relacionadas con el contexto a través de textos cortos, frases, libros y comparando con el español. Los docentes aducen que en Facebook se pueden utilizar muchas herramientas educativas pero no son aprovechadas académicamente, desaprovechando la oportunidad del aprendizaje en línea desde su hogar y/o en tiempos libres.

Como estrategia de aprendizaje se logró observar que los estudiantes en equipos conversan sobre ejercicios orientados por el docente, promoviendo las habilidades de speaking y listening. De igual manera se observó que el docente orienta la lectura de documentos y los estudiantes realizan síntesis y ensayos sobre el tema logrando promover las habilidades de writing y listening.

\section{Facebook como herramienta didáctica para} el desarrollo de la comprensión auditiva, pronunciación, gramática y vocabulario del idioma Inglés.

Los programas de estudios de las asignaturas Gramática I, Ingles Integral I y II proponen realizar diferentes ejercicios para desarrollar la comprensión auditiva tales como: Realizar trabajos en pareja donde los estudiantes pongan en práctica la teoría mediante la creación de conversaciones cortas, entrevistas con ejercicios escritos y narraciones cortas, así como prácticas orales; como diálogos, entrevistas; y escritas como redacción de oraciones de diferentes tipos, elaboración de cartas solicitando consejos o sugerencias así como realizar la repetición de sonidos (Canciones).

La comprensión auditiva precede a la producción en todos los casos del aprendizaje de un idioma, y no puede haber producción a menos que se dé el estímulo lingüístico (linguistic input) y que éste, a su vez, se convierta en material comprensible (comprehensible intake) para la persona que escucha. La comprensión es importante no sólo porque precede la producción lógica y cronológicamente, sino especialmente porque constituye el mecanismo básico por medio del cual se internalizan las reglas del lenguaje.

En el pilotaje realizado en una página en Facebook las y los estudiantes realizaron ejercicios relacionados con la comprensión auditiva, se colgaron videos y canciones donde las y los estudiantes escuchaban detenidamente, posteriormente realizaba comentarios sobre el contenido, logrando la participación activa de todos los estudiantes. Ver imagen 1, a través de la música, las películas, series, documentales podemos comprender un poco más el Inglés que a veces es tan difícil de entenderlo. El Facebook se convierte en una herramienta poderosa para trabajar la comprensión auditiva por todos los recursos que se pueden incorporar en dicha red social.

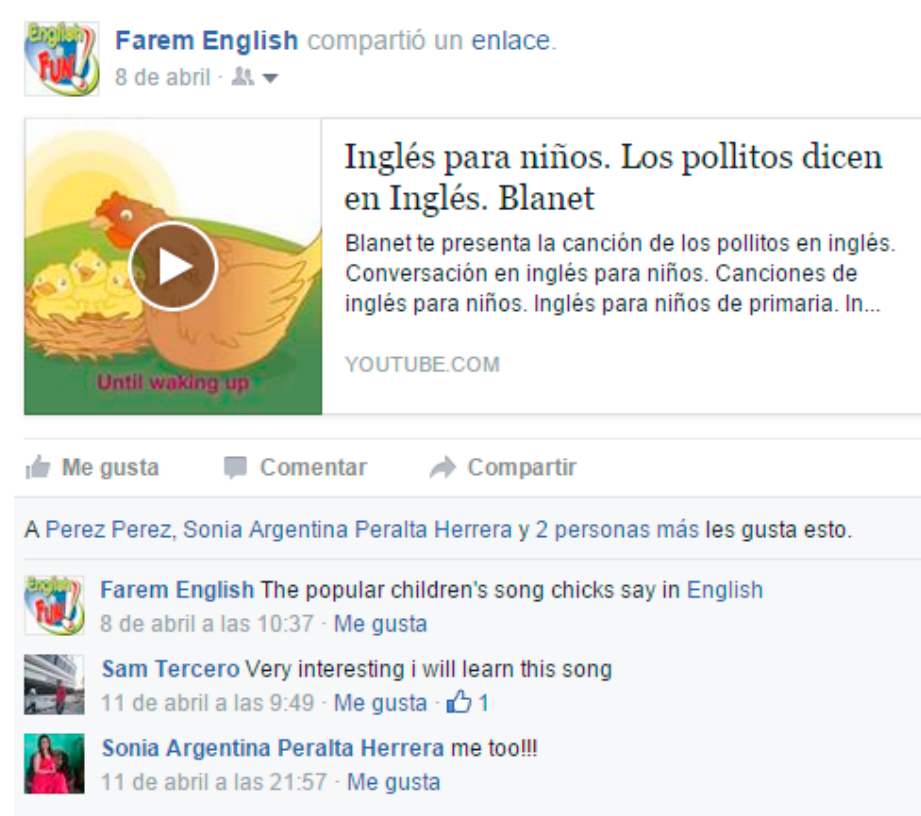

Imagen 1, Participación estudiantil en Facebook 
Utilizando la herramienta Facebook se puede desarrollar la comprensión auditiva utilizando enlaces a sitios web: Elllo (http://www.elllo.org/), Agenda Web (http://www.agendaweb.org/), Listen and Write (http:// www.listen-and-write.com/), Sozo Exchange (http:// sozoexchange.com/) y BBC (http://www.bbc.com/).

Sobre la Pronunciación los programas de estudios de Inglés proponen lo siguiente: Proporcionar un horario donde las y los estudiantes completen con actividades que realizarán durante la semana, creación de diálogos y conversaciones cortas. Utilizando Facebook se puede utilizar el método LRC (Listen-Record-Compare) para mejorar tu pronunciación: grabarás tu voz, te escucharás y podrás comparar tu pronunciación con la del Inglés nativo para este ejercicio se pueden utilizar las herramientas Fotobabble y Voicethrad.

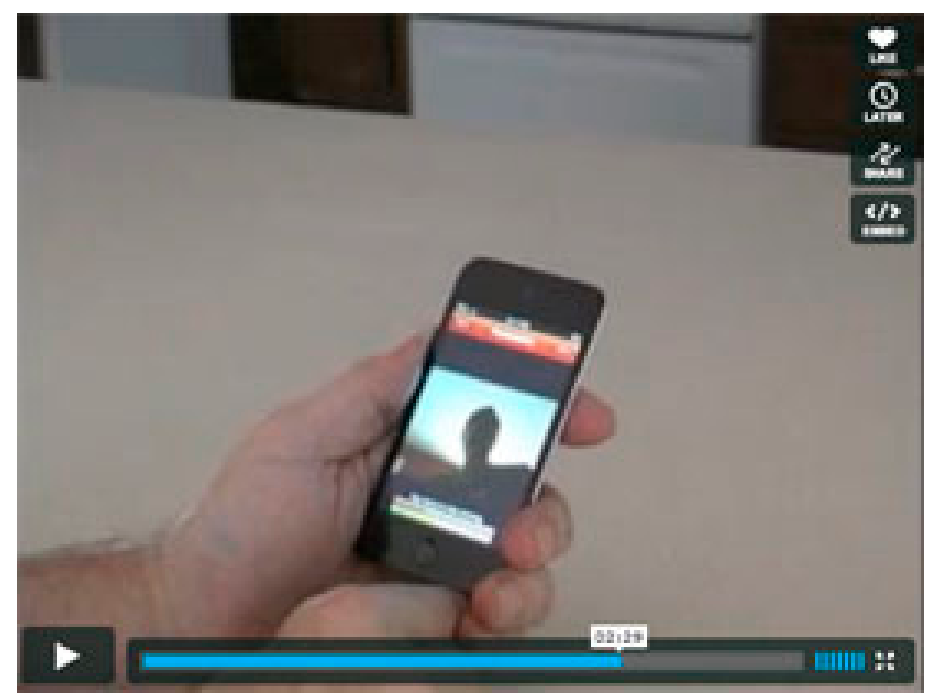

Imagen 2, Fotobabble en Facebook

Sobre la Gramática los programas de estudio proponen utilizar: ejercicios de completación o selección, redactar párrafos. Estas actividades coinciden con las que el docente utiliza en el aula de clase como guía de aprendizaje que incluye actividades con oraciones cortas, completar frases, relacionar textos. La gramática se puede fortalecer utilizando conversaciones grupales en Facebook, reflexiones sobre imágenes con comentarios, utilizando herramientas como educaplay y padlet. En la imagen 1, se muestra la participación de las y los estudiantes a traves de comentarios realizados sobre una imagen.

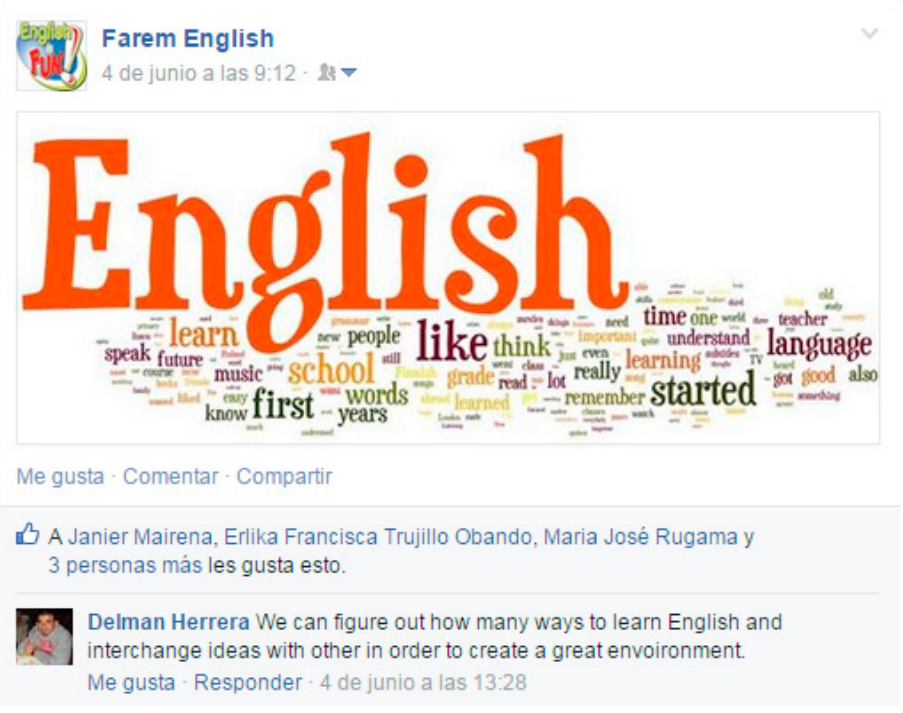

Imagen 3, Reflexionando sobre imágenes en Facebook

Para el Vocabulario a través de diálogos, juegos, canciones y lecturas. Se sugiere hacer diferentes actividades de speaking en grupos o parejas, por ejemplo, proveer fotos de personas famosas que han hecho aportes para el desarrollo de la humanidad, de lugares y de cualquier otra situación etc. Al consultar a los docentes, sobre, si el uso de la red social Facebook favorecía el desarrollo de las habilidades básicas del idioma Inglés en las y los estudiantes.

- El docente 1 respondió: "si, siempre y cuando se utilice para lo que es, auto aprendizaje".

- El docente 2 respondió: "Si claro, se pueden poner lecturas, videos, ejercicios prácticos entre otros".

- El docente 3 respondió: "Por supuesto que sí". 
Farem English

1 de abril - $41=$

Dear students this site was created with the goal that you can use to develop English skills.

Forward to sharing learning experiences

Me gusta - Comentar - Compartir

A Edith Hernandez, Sonia Argentina Peralta Herrera y Elizabet Davila Gomez les gusta esto.

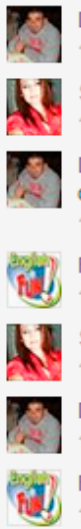

Delman Herrera Thanks for it.

I de abril a las 13:06 - Ya no me gusta - 13

Sonia Argentina Peralta Herrera Thank you for share with us!!

1 de abril a las 14:30 - Me gusta

Delman Herrera You're welcome guys .. We are here to learn from each and ther. That's the deal how it works out.

1 de abril a las 14:31 - Me gusta - 31

Farem English welcome Sonia Argentina Peralta Herrer

1 de abril a las 14:35 - Me gusta - 131

Sonia Argentina Peralta Herrera Good idea teacher !!! I like it .

1 de abril a las 14:37 - Me gusta

Delman Herrera What have you done so far Sonia?

1 de abril a las 14:38 - Me gusta - 131

Farem English Sonia Thanks, this will be a space to share learnings

1 de abril a las 14:39- Me gusta - 1

Imagen 4, Interacción docente-estudiante / estudianteestudiante

Los docentes consideran que si esta red social es utilizada como herramienta de aprendizaje, se podría aprovechar para colgar lecturas, videos, ejercicios prácticos etc.

Plan de capacitación para docentes sobre diferentes herramientas educativas utilizando la red social Facebook como estrategia didáctica con el fin de favorecer el desarrollo de las habilidades básicas del idioma Inglés en los y las estudiantes.

En la tabla nrol se muestran resultados donde 137 estudiantes de 138 participantes en este estudio están dispuestos a participar en actividades que las y los docentes promuevan en la red social Facebook con el fin de favorecer el desarrollo de las habilidades básica del idioma Inglés.
¿Estarías dispuesto a participar en actividades que tus docentes promuevan en la red social Facebook con el fin de favorecer el desarrollo de las habilidades básicas del idioma Inglés?

\begin{tabular}{lllll}
\hline Válidos & Frecuencia & Porcentaje & $\begin{array}{c}\text { Porcentaje } \\
\text { válido }\end{array}$ & $\begin{array}{c}\text { Porcentaje } \\
\text { acumulado }\end{array}$ \\
\hline Si & 1 & 0.7 & 0.7 & 0.7 \\
No & 137 & 99.3 & 99.3 & 100 \\
Total & 138 & 100 & 100 & \\
\hline
\end{tabular}

Tabla 1. Resultados de encuesta aplicada a estudiantes

Estos datos demuestran que las y los estudiantes ven en Facebook una herramienta útil para el desarrollo de las habilidades básicas del idioma Inglés. Por su parte el $86 \%$ de los docentes dijo estar de acuerdo en promover actividades en Facebook con el fin de favorecer el desarrollo de las habilidades básica del idioma Inglés.

¿Cuál o cuáles de estas actividades te gustaría realizar en una página de Facebook cuyo propósito sea el desarrollo de las habilidades básicas del idioma Inglés?

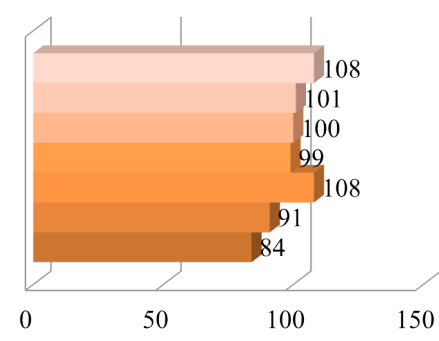

Realizar actividades interactivas en inglés Conversaciones grupales sobre un contenido en inglés * Ver películas educativas en inglés Reflexionar sobre imágenes con mensajes en inglés - Leer contenido educativo en inglés - Grabar vídeos de conversaciones en inglés - Grabar voz en inglés

Gráfico5. Actividades en Facebook

En el Gráfico No. 5 se muestran las actividades que les gustaría realizar a las y los estudiantes en una página de Facebook cuyo propósito sea el desarrollo de las habilidades básicas del idioma Inglés.

Este estudio incorpora una propuesta de plan de capacitación compuesto por dos sesiones de capacitación a desarrollarse en 5 horas cada sesión, en la primera sesión se pretende desarrollar competencias en el participante sobre el uso de la web 2.0 con el fin de desarrollar las habilidades básicas del idioma Inglés entre los contenidos a desarrollar se encuentran: uso de sitios web relacionados con el Inglés, Fotobabble, Voicethrad y Educaplay. 
En la segunda sesión se pretende desarrollar competencias en el participante sobre el uso de Facebook como herramienta didáctica con el fin de desarrollar las habilidades básicas del idioma Inglés entre los contenidos a desarrollar se encuentran: Configuración y privacidad de Facebook, grupos de interés, chat de grupo, comentarios, trabajo con imágenes, sonidos, videos y documentos.

\section{CONCLUSIONES}

La sociedad del conocimiento se caracteriza por la velocidad con que día a día se crean nuevos conocimientos y la rapidez con que éstos evolucionan. En la UNAN-Managua se concibe el aprendizaje como un proceso dinámico que parte de las experiencias, conocimientos e intereses previos que ya poseen las y los estudiantes.

Las tecnologías de la información y comunicación (TIC) han adquirido gran relevancia, principalmente a partir del amplio uso de la red Internet, siendo el educativo uno de sus más importantes campos de acción, docentes y estudiantes de la carrera Licenciatura en Inglés de la FAREM Estelí disponen del servicio de internet en toda la Facultad.

Facebook es la red social más utilizada por docentes y estudiantes de la carrera de Inglés razón por la cual es necesaria su valoración para facilitar la distribución de contenidos en un entorno educativo.

Las y los estudiantes así como las y los docentes consideran que al utilizar Facebook como herramienta didáctica y de aprendizaje se lograría desarrollar las habilidades básicas del idioma Inglés.

Las actividades que se pueden realizar en Facebook con el fin de favorecer el desarrollo de las habilidades básicas son: Grabar voz en Inglés, grabar vídeos de conversaciones en Inglés, leer contenido educativo en Inglés, reflexionar sobre imágenes con mensajes en Inglés, ver películas educativas en Inglés, conversaciones grupales sobre un contenido en Inglés y realizar actividades interactivas en Inglés (crucigramas, rellenar huecos, test, emparejamiento, verdadero y falso).

El fin justifica los medios: El uso de Facebook como herramienta TIC por sí sola no aporta al desarrollo de las habilidades básicas del idioma inglés se necesita del uso didáctico de esta poderosa herramienta muy utilizada, hoy en día, para poder desarrollar las habilidades básicas de dicho idioma. El docente debe planificar estrategias de enseñanza mediadas por las TIC (en este caso Facebook), con el objetivo de motivar el desarrollo de las habilidades básicas del idioma Inglés partiendo del interés que las y los estudiantes muestran en el uso de esta herramienta TIC.

\section{"La red social Facebook conecta personas, la didáctica aprendizajes, pero unidas construyen conocimientos" --Luis E. Saavedra-}

\section{RECONOCIMIENTOS}

El autor que presenta esta comunicación intervino como facilitador de esta experiencia, bajo la dirección y colaboración del profesorado de la Maestría: Pedagogía con mención en Docencia Universitaria. En este sentido, quiero expresar mi gratitud para todo el profesorado, en particular para mi tutor de tesis: MS.c. Franklin Jesús Solís Zúniga por su ayuda, confianza, paciencia, estímulo y calidad profesional, al ser guía fundamental en la realización de mi trabajo de investigación. Agradezco a todos los participantes en este estudio, a mis compañeros docentes de Inglés, así como a las y los estudiantes de la carrera de Inglés mi más profundo agradecimiento por su colaboración. 


\section{BIBLIOGRAFÍA}

Cabero, J., \& Gisbert, M. (2005). La formación en Internet. Guía para el diseño de material didáctico (Primera ed.). Sevilla: Editorial MAD, S.L. Editorial.

Castells, M. (06 de 09 de 2011). Sociología Comtemporánea. Obtenido de Sociología Comtemporánea: http://sociologiac. net/2011/09/06/descarga-la-galaxia-internetmanuel-castells/

Hernández, R., Fernández, C., \& Baptista, P. (2006). Metodología de la investigación (Cuarta ed.). México: Mc Graw Hill.

López de la Madrid, Flores, \& Espinoza de los Monte. (2013). Uso educativo de Facebook por el docente universitario. Guadalajara.
Marqués, P. (28 de 12 de 2012). 3ciencias. Obtenido de 3ciencias: http://www.3ciencias.com/wp-content/ uploads/2013/01/impacto-de-las-tic.pdf

Pérez-Sabater, C. (12 de 06 de 2012). Linguistik online. Obtenido de Linguistik online: http://www. linguistik-online.de/56_12/perez-sabater.html

Rojas Bonilla, P. (2013). Reforzando el aprendizaje del idioma Inglés en el aula con el apoyo y uso de las TIC. Hidalgo, México.

Tobón, S. (2006). Formación basada en competencias. Pensamiento complejo, Diseño curricular $y$ didáctica. (Segunda ed.). Bogotá, Colombia: ECOE Ediciones Ltda.

Tobón, S. (2006). Formación basada en competencias. Pensamiento complejo, Diseño curricular $y$ didáctica. (Segunda ed.). Bogotá, Colombia: ECOE Ediciones Ltda. 